\title{
Ciência da Informação como área do conhecimento: abordagem no contexto da pesquisa e da Pós-Graduação no Brasil
}

Rosali Fernandez de Souza

Pesquisadora Titular do Instituto Brasileiro de Informação em Ciência e Tecnologia (IBICT); Pesquisadora CNPq; Representante da área de CI no CNPq no período 2005-2008

Ida Regina Chitto Stumpf

Professora Titular do Departamento de Ciências da Informação e do Programa de Pós-Graduação em Comunicação e Informação/UFRGS; Pesquisadora CNPq; Coordenadora Adjunta CSA1/CAPES.

Mostra a evolução da representação da Ciência da Informação como área do conhecimento em classificações de ciência e tecnologia usadas por agências de fomento no Brasil. Apresenta panorama da Ciência da Informação através dos programas de pós-graduação, salientando aspectos de institucionalização e desenvolvimento. Focaliza também as linhas de pesquisa dos onze programas atuais, mostrando que se orientam especialmente para a Gestão, a Organização e a Transferência da Informação. Ao final são apresentadas algumas perspectivas para a área.

Palavras-chave: Ciência da Informação; Pesquisa; PósGraduação; Agências de fomento; Brasil.

\section{Information science as area of knowledge: viewed through research and Postgraduation studies in Brazil}

Describes how Information Science is represented as area of knowledge in classifications used by research agencies in science and technology in Brazil. A panorama of 
Information Science is viewed through current postgraduation programmes, mainly considering institutional and development aspects. The lines of research of the eleven programmes indicate information management, organization and transfer as main fields of interest. The analyses revealed perspectives to the development of the area in the country.

Keywords: Information Science; Research. Postgraduation studie;. Financing Agencies; Brazil.

\section{Introdução}

A Ciência da Informação (CI) é caracterizada como uma ciência interdisciplinar por natureza. Ao tratar de questões voltadas para a geração, comunicação e apropriação do conhecimento abrange um largo espectro de possíveis temáticas de interesse por estudiosos oriundos de diferentes áreas de formação acadêmica. Consequentemente, como campo de pesquisa e ensino apresenta uma riqueza impar de possíveis metodologias de abordagem e propicia o desenvolvimento de diferentes processos, métodos e técnicas de coleta, tratamento e recuperação da informação.

A extensão e a diversidade de campos de atuação da Ciência da Informação permitem diferentes olhares para a sua definição e constituição enquanto área de conhecimento. O artigo Information Science de Tefko Saracevic publicado no final do século passado (SARACEVIC 1999) apresenta e discute duas perguntas básicas: "What is information science" e How is information science, or for that matter any field, to be defined. O trabalho Knowledge Map of Information Science : issues, principles and implications de autoria de Zins, apresenta resultado de investigação oriunda de trabalho colaborativo com especialistas acadêmicos da área no esforço de responder as seguintes perguntas : "What is Information Science?, What are its boundaries? And its basic buildings blocks? (ZINS, 2009).

É reconhecido e comprovado que a representação de uma área do saber é uma atividade difícil e complexa. A principal dificuldade está em determinar e nomear seus principais campos de atuação, pois nenhuma área é tão especializada ou tão abrangente quanto possa parecer num primeiro instante. Além dessa natural dificuldade, a Ciência da Informação apresenta características peculiares por ser uma área de desenvolvimento recente em relação a outras áreas do conhecimento, e por congregar professores, pesquisadores e profissionais de diferentes formações acadêmicas com atuações diversificadas no campo da informação. Essas características, se por um lado motivam e enriquecem sobremaneira o seu desenvolvimento científico, por outro lado causam dificuldades na sua 
representação, enquanto área de conhecimento, em tabelas e esquemas de classificação para diferentes propósitos de uso.

O objetivo deste artigo é mostrar como a CI se "define" como área do conhecimento no contexto da gestão e avaliação em agências de fomento à pesquisa e ao ensino no Brasil. Especificamente, através de sua representação na Tabela de Áreas do Conhecimento (TAC) e nos Comitês de Assessoramento do CNPq (Conselho Nacional de Desenvolvimento Científico e Tecnológico), e a configuração das linhas de pesquisa nos programas de pós-graduação em Ciência da Informação no Brasil. Certamente que os resultados aqui apresentados refletem momentos circunstanciais e situacionais no espaço e no tempo. De qualquer forma, revelam características histórico-culturais significativas para estudos da institucionalização e desenvolvimento Ciência da Informação no Brasil.

\section{A Ciência da Informação nas agências de fomento}

As classificações escolhidas para mostrar a representação da CI nas agências de fomento foram a Tabela de Áreas do Conhecimento em uso pelo CNPq e pela CAPES (Coordenação de Aperfeiçoamento de Pessoal de Nível Superior), e a sistematização das grandes áreas e das áreas do conhecimento nos comitês de assessoramento do CNPq (SOUZA, 2008).

\subsection{Na tabela de áreas do conhecimento}

A Tabela de Áreas do Conhecimento (TAC) organiza o universo de ciência e tecnologia do país para finalidades gestão e avaliação em níveis hierárquicos de agregação. A primeira versão da classificação data de 1976 e a segunda versão de 1982. A versão de 1984 é que está em vigor até hoje tanto no CNPq como na CAPES, com poucas modificações no tempo. Nas últimas duas décadas foram várias as iniciativas de atualização, mudanda ou reformulação, mas até o momento permanece em vigor a versão de 1984. A seguir, uma breve descrição das diferentes versões da TAC no tempo, especificando a representação da CI como área do conhecimento.

A TAC 1976 (CNPq 1976) apresenta, em ordem alfabética, 42 áreas do conhecimento que se subdividem em subáreas e especialidades. Nesta primeira versão da TAC, a CI não é representada como área do conhecimento. Aparece como subárea da área Comunicação e é nomeada como Ciências da Informação. Como especialidades das Ciências da Informação são nomeados Sistemas de Informação, Biblioteconomia e Documentação

A versão TAC de 1982 (CNPq 1982) apresenta estrutura hierárquica em quatro níveis: grande área, área, subárea e especialidade do conhecimento. Compreende o conjunto de seis grandes áreas ordenadas em ordem alfabética: Ciências Agrárias, Ciências Biológicas, Ciências da Engenharia, Ciências Exatas e da Terra, Ciências Humanas, Sociais e Artes e Ciências da Saúde. Nesta versão da TAC a Ciência da 
Informação é considerada área do conhecimento, na grande área Ciências Humanas, Sociais e Artes. A sua nomeação nomeação da área, no entanto, incorpora a Biblioteconomia e a Arquivologia. A área é constituída pelas subáreas Teoria da Informação e Tratamento da Informação, que são subdivididas por especialidades que tratam de aspectos teóricos e práticos da área envolvidos nos processos de tratamento da informação e de técnicas de recuperação da informação

A TAC 1984, versão em vigor, mantém os quatro níveis hierárquicos da versão anterior. Para os propósitos da presente discussão é importante ressaltar que a finalidade da TAC foi assim explicitada quando da publicação desta versão: "A classificação das áreas do conhecimento tem finalidade eminentemente prática, objetivando proporcionar aos órgãos que atuam em C\&T, uma maneira ágil e funcional de agregar suas informações". (CNPq 1984)

A definição dos objetivos da TAC na década de oitenta merecem atenção para reflexão quanto à íntima relação existente entre uma estrutura, tabela ou esquema de classificação e os objetivos propostos de sua construção. As duas declarações claras de ter "finalidade eminentemente prática" e de se propor a ser "uma maneira ágil e funcional de agregar informações" explicitam a intenção e a necessidade da representação das áreas do conhecimento na TAC. A primeira observação deixa transparecer que a prioridade dos critérios de decisão foi definida em função da praticidade na sistematização de dados, ainda que em detrimento de outros possíveis critérios de sistematização de natureza filosófica ou epistemológica de áreas do conhecimento em ciência e tecnologia. A segunda observação explicita a decisão de adotar a estrutura hierárquica de arranjo como uma forma ágil e funcional de agregar informações para uso das agências de fomento. $O$ ponto fundamental de reflexão se dá frente às implicações decorrentes dessas decisões, de onde decorrem as inúmeras críticas à TAC pelas comunidades científicas.

Na versão da TAC de 1984, a estrutura hierárquica do universo de ciência e tecnologia contempla oito grandes áreas do conhecimento que se subdividem em áreas, subáreas e especialidades. A sequência das grandes áreas deixa de ser alfabética e sugere uma sistematização que envolve as ciências do mundo, da vida e do homem, assim nomeadas: 1. Ciências Exatas e da Terra, 2. Ciências Biológicas, 3. Engenharias, 4. Ciências da Saúde, 5. Ciências Agrárias, 6. Ciências Sociais Aplicadas, 7. Ciências Humanas, e 8. Lingüística, Letras e Artes.

Na versão TAC 1984, a Ciência da Informação está alocada no conjunto das 13 áreas da grande área Ciências Sociais Aplicadas que são: Direito, Administração,

Economia, Arquitetura e Urbanismo, Planejamento Urbano e Regional, Demografia, Museologia, Comunicação, Serviço Social, Economia Doméstica, Desenho Industrial e

Turismo. Nesta versão, que corresponde à TAC em vigor, a área da Ciência da Informação compreende três subáreas nomeadas como: 
Teoria da Informação, Biblioteconomia e Arquivologia, cada uma com especialidades próprias que enfatizam técnicas e processos de tratamento e recuperação da informação.

O Quadro 1 a seguir sintetiza a área da Ciência da Informação nas versões da TAC de 1976, 1982 e 1984 proporcionando uma visualização da sua evolução como área do conhecimento no tempo.

\begin{tabular}{|l|c|}
\hline \multicolumn{2}{|c|}{ TAC 1976 } \\
\hline Área & Comunicação \\
\hline Subárea & Ciências da Informação \\
Especialidades & Sistemas de Informação \\
& Biblioteconomia e Documentação \\
& Outras (Especificar) \\
\hline \multicolumn{2}{|c|}{ TAC 1982 } \\
\hline Grande Área & Ciências Humanas, Sociais e Artes \\
\hline Área & Ciência da Informação, Biblioteconomia e Arquivologia \\
\hline Subárea & Teoria da Informação \\
Especialidades & Teoria Geral da Informação \\
& Processos da Comunicação \\
& Teoria da Classificação \\
& Representação da informação \\
Subárea & Métodos Quantitativos. Bibliometria \\
Especialidades & Tratamento da Informação \\
& Técnicas de recuperação da informação \\
& Processos de disseminação da informação \\
\hline \multicolumn{2}{|c|}{ Organização de arquivos } \\
\hline Grande Área & TAC 1984 \\
\hline Área & Ciências Sociais Aplicadas \\
\hline Subárea & Ciência da Informação \\
Especialidades & Teoria da Informação \\
& Teoria Geral da Informação \\
\hline Subárea & Processos da Comunicação \\
Especialidades & Representação da Informação \\
& Biblioteconomia \\
& Teoria da Classificação \\
\hline Subárea & Métodos Quantitativos. Bibliometria \\
Especialidades & Técnicas de Recuperação da Informação \\
& Processos de Disseminação da Informação \\
\hline & Orquivologia \\
& Organização de Arquivos \\
\hline
\end{tabular}

Quadro 1 Ciência da Informação nas versões da Tabela de Áreas do Conhecimento

Fonte: CNPq 1976, CNPq, 1982 e CNPq 1984

Comparando as versões da TAC no tempo observamos que a CI inicia sua representação como subárea da área Comunicação na década de 70 e nomeada como Ciências da Informação. Na década de 80 passa a ser representada na hierarquia como área do conhecimento nomeada como Ciência da Informação com Biblioteconomia e Arquivologia Com a expansão no número das grandes áreas na TAC em 1984 é criada a grande área das Ciências Sociais Aplicadas, e a CI se firma como área do conhecimento. A análise das subáreas e especialidades no tempo revela, independentemente de modificações em nomeações, aspectos teóricos 
da informação e aspectos práticos compreendendo os processos de tratamento, disseminação, recuperação e análise da informação.

A partir de data não identificada e até 2007 a versão eletrônica da TAC apresentou mais uma grande área nomeada como 9 - Outros. Esta grande área compreendia vinte e quatro itens, arrolados em ordem alfabética incluindo profissões, nomes de cursos, além de áreas, especialidades e grandes áreas do conhecimento. Entre as grandes áreas aparecia "Ciências Sociais". Este fato merece atenção uma vez que na estrutura da TAC estavam especificadas como grandes áreas Ciências Humanas, Ciências Sociais Aplicadas e Línguística, Letras e Artes.

A representação do universo do conhecimento em grandes áreas e áreas apresentou inúmeras formas de divisões e subdivisões ao longo do tempo, fruto do próprio desenvolvimento do conhecimento. Muitos estudiosos já se dedicaram a essas diferenças e, no caso das Ciências Sociais, a linha divisória com as Humanidades está se tornando cada vez mais difusa e fica cada vez mais difícil de ser evidenciada. Meadows apresenta a citação do sociólogo George Caspar Homans que diz: "entre as ciências sociais e muitas das chamadas humanidades não se pode traçar uma fronteira intelectual: todas são ciências sociais (ou, se preferirem, todas são humanidades)". (MEADOWS, 1999)

Atualmente a composição da grande área "9 - Outros" na TAC apresenta nova configuração com as seguintes subáreas: Bioética, Ciências Ambientais, Defesa e Divulgação Científica. À exceção das Ciências Ambientais, os demais itens são nomeados como Comitês Temáticos nas agregações dos Comitês de Assessoramento do CNPq.

Nas últimas duas décadas foram várias as iniciativas de atualização ou mudança da TAC no CNPq e na CAPES, mas até o momento permanece em vigor a versão de 1984 . Souza sistematizou os principais problemas apontados da TAC em vigor por pesquisadores de diferentes áreas do conhecimento, assim como as sugestões e propostas de revisão (SOUZA, 2004).

Os pesquisadores caracterizam a TAC em vigor como: defasada em relação à realidade da pesquisa e conseqüentemente sua representação na Tabela; inadequada, anacrônica e pobre em termos de representação das pesquisas geradas no país; deficiente em termos de evolução natural e da forma como a pesquisa se desenvolveu nas instituições de ensino e pesquisa com programas de pós-graduação no país; limitada em termos de subáreas e especialidades para a devida classificação de projetos de pesquisa: apresenta lacunas, imprecisões descritivas e abrangências insuficientes; necessita de modernização nos tópicos.

Quanto a sugestões de mudanças da TAC, a comunidade cientifica apontou como principais parâmetros norteadores: a classificação não deve ser muito fragmentária, nem demasiadamente abrangente; a necessidade de adotar critérios mínimos nas subdivisões da área em subáreas e no detalhamento das especialidades; a proporção de subáreas deve ter como princípio a prática da investigação vigente; as subáreas devem procurar deter as denominações já consagradas entre os pesquisadores, mesmo 
que não reflitam estritamente os recortes lógicos organizadores da área enquanto disciplina científica; a indicação de subáreas não deve ser exaustiva.

Os pesquisadores consideraram ainda que uma proposta de revisão/atualização da TAC deveria: refletir referências habituais dos pesquisadores a tipos específicos de problemas; ser consensualmente aceita pela comunidade como rigorosa, abrangente e suficiente (sem lacunas); ser pensada em termos de futuro; apresentar compatibilidade com classificações internacionais, porém resguardadas as características nacionais.

As considerações acima revelam evidenciam a complexidade e o quanto é difícil e delicado o processo de construção ou de atualização ou mesmo de reformulação de uma tabela de áreas do conhecimento no âmbito das agências de fomento.

Tomando como ponto de partida que toda classificação está condicionada a propósitos específicos de uso, a Comissão Especial de Estudos CNPq-CAPES-FINEP criada em 2005 para propor uma nova TAC identificou como principais finalidades da TAC: dar suporte ao planejamento, gestão e avaliação dos programas das agências; compatibilizar as necessidades da comunidade científica visando facilitar a avaliação de propostas de fomento; e favorecer o acompanhamento e a avaliação de políticas públicas em ciência, tecnologia e inovação no país (CNPq 2005).

A Comissão também trabalhou nos conceitos de grande área, área, subárea e especialidade na TAC, definindo-os como segue:

Grande Área: aglomeração de diversas áreas do conhecimento em virtude da afinidade de seus objetos, métodos cognitivos e recursos instrumentais refletindo contextos sociopolíticos específicos;

Área: conjunto de conhecimentos inter-relacionados, coletivamente construído, reunido segundo a natureza do objeto de investigação, com finalidades de ensino, pesquisa e aplicações práticas;

Subárea: segmentação da área do conhecimento estabelecida em função de estudo e de procedimentos metodológicos reconhecidos e amplamente divulgados;

Especialidade: caracterização temática da atividade de pesquisa e ensino. A proposta da Comissão considera que as especialidades deveriam ser excluídas da hierarquia, o que possibilitaria o seu enquadramento em diferentes grandes áreas, áreas e subáreas (CNPq 2005).

$\mathrm{Na}$ proposta de revisão da TAC da referida Comissão, a área da Ciência da Informação ficaria assim representada no seu conjunto de subáreas: Fundamentos da Ciência da Informação; Organização do Conhecimento; Gestão da Informação; Disseminação e Uso da Informação; Política e Economia da Informação; e Tecnologias da Informação.

Por ocasião da revisão da TAC em 2005, a Arquivologia apresentou proposta de criação de área em separado compreendendo as seguintes subáreas: Fundamentos de Arquivologia; Gestão Arquivística; Métodos 
Arquivísticos; e Arquivologia Especializada. Para Biblioteconomia, a Comissão propôs a criação de área em separado com as seguintes subáreas: Fundamentos da Biblioteconomia; Gestão de Unidades de Informação; Teoria e Técnicas Documentárias; e Documentação Especializada. A Museologia também apresentou proposta de criação de área $\mathrm{m}$ separado, com as seguintes subáreas: Fundamentos Teóricos da Museologia; Museologia Aplicada; e Temas Específicos em Museologia.

\subsection{Nos comitês assessores do CNPq}

As áreas do conhecimento nos Comitês Assessores e Temáticos do CNPq estão agregadas em quinze coordenações, distribuídas em três grandes áreas, a saber: Ciências Humanas e Sociais Aplicadas, Ciências da Vida e Ciências Exatas e da Terra e Engenharias.

As Ciências Humanas e Sociais Aplicadas compreendem duas coordenações de pesquisa: Ciências Humanas e Sociais (COCHS); e Ciências Sociais Aplicadas e Educação (COSAE). A Ciência da Informação compõe o CA-AC Artes, Ciência da Informação e Comunicação da Coordenação de Pesquisa das Ciências Humanas e Sociais (COCHS).

$\mathrm{Na}$ classificação das demandas de financiamento para o Comitê Assessor do CNPq, a Ciência da Informação aparece com as seguintes 'áreas de interesse' a própria CI no conjunto de Teoria da Informação, Processos de Comunicação, Representação da Informação, Biblioteconomia, Técnicas de Recuperação da Informação, Processos de Disseminação da Informação e Arquivologia.

A Museologia, como ainda não conta com representação de área, tem a sua demanda analisada pelo Comitê CA-AC.

$\mathrm{Na}$ classificação dos Comitês Assessores do CNPq observa-se que a grande área das Ciências Humanas e Sociais Aplicadas apresenta distribuição das áreas do conhecimento em duas coordenações de pesquisa: uma de Ciências Humanas e Sociais e outra Ciências Sociais Aplicadas e Educação. A Ciência da Informação que na TAC é representada como área das Ciências Sociais Aplicadas, na organização dos Comitês de Assessoramento aparece na coordenação das Ciências Sociais e Humanas.

\section{A pós-graduação em Ciência da Informação}

No Brasil, a CI teve uma data fixa para iniciar institucionalmente: foi em 1970, quando foi criado o primeiro curso de pós-graduação, em nível de mestrado, pelo então Instituto Brasileiro da Bibliografia e Documentação - IBBD, hoje Instituto Brasileiro de Informação em Ciência e Tecnologia - IBICT, em convênio com a Universidade Federal do Rio de Janeiro - UFRJ. O curso do IBBD, pioneiro no país e na América Latina, marcou a entrada da CI no Brasil. Foi nesta época que vieram os primeiros professores estrangeiros, principalmente americanos, para ministrar as disciplinas que compunham o currículo do programa, apresentar seminários e orientar as dissertações: Jessé H. Shera, La Vahn 
Marie Overmyer, Tefko Saracevic, Frederick Wilfrid Lancaster, Derek Solla Price, Bert Roy Boyce, Ingetraut Dahlberg, Suman Datta, Jack Mills e outros (Pinheiro, 2006).

A partir dessa data, outros cursos de pós-graduação stricto sensu em CI foram criados, primeiramente como Mestrado em Biblioteconomia, e só na década de 90 assumiram a denominação de Ciência da Informação e ampliaram sua atuação para o nível de doutorado. Também a pesquisa em Ciência da Informação no Brasil está profundamente vinculada às atividades da pós-graduação, uma vez que, como campo de investigação, a CI desenvolve-se principalmente neste nível (STUMPF, 2008).

Os principais fatores que influenciaram a implantação da pósgraduação em CI no Brasil foram: a própria necessidade de formação de recursos humanos especializados, a capacitação de docentes para as instituições de ensino superior e a conscientização da importância do desenvolvimento da pesquisa em informação (POBLACIÓN, 1993).

\subsection{Os programas de pós-graduação em Ciência da Informação}

Os Programas de Pós-Graduação em Ciência da Informação (PPGCIs) estão localizados, segundo a classificação das áreas do conhecimento definida pela CAPES, dentro da grande área das Ciências Sociais Aplicadas, na área CSA 1 - Ciências Sociais Aplicadas 1, que contempla as subáreas da Comunicação, Ciência da Informação e Museologia. A junção das três subáreas é muito díspar em relação ao número de cursos: a Comunicação tem 34 cursos, a CI tem 11 cursos e Museologia, até o ano de 2009, tem apenas 1 curso, em nível de mestrado.

De acordo com a CAPES, os programas devem apresentar estrutura manifesta por áreas de concentração, que são "[. . .] indicações que condensam ou retratam as intenções dos cursos" (FAUSTO NETO, 1996, p.86), e linhas de pesquisa que são a representação de temas aglutinadores de estudos científicos investigativos, de onde se originam projetos de pesquisa com afinidades entre si (CAPES, 2009).

São onze os programas de pós-graduação em Ciência da Informação hoje no Brasil, dos quais cinco são nos níveis de Doutorado e Mestrado, cinco de Mestrado e um de Mestrado Profissional. De acordo com o nível que desenvolvem ( $M=$ Mestrado e $D=$ Doutorado), ano de início, áreas de concentração e linhas de pesquisa, os programas são apresentados a seguir: 
Ciência da Informação como área do conhecimento: abordagem no contexto da pesquisa e da Pós-Graduação no

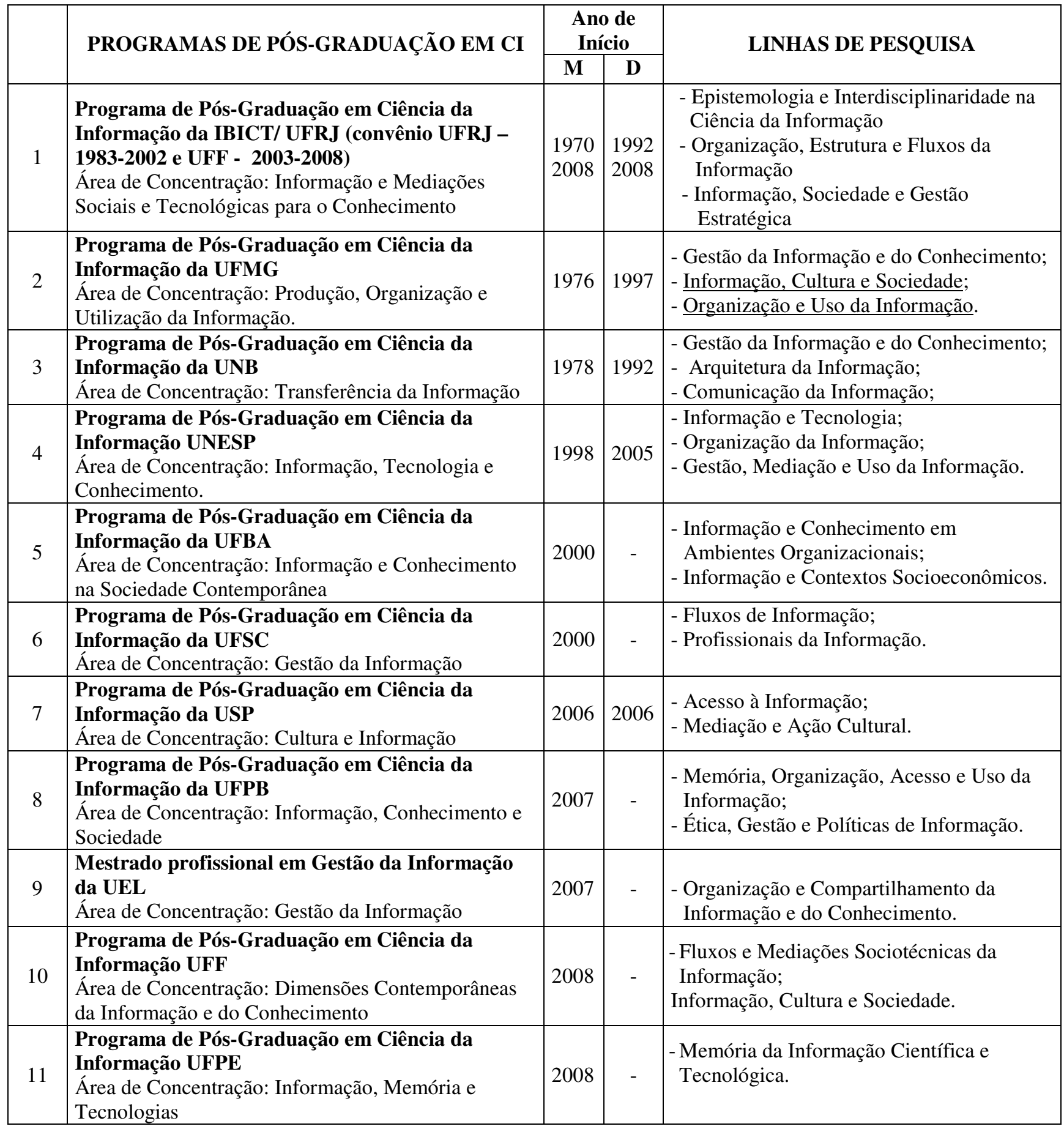

Quadro 2 Estrutura dos Programas de Pós-Graduação em Informação no Brasil,reconhecidos pela CAPES em 2009.

Fonte: <http://www.capes.gov.br/capes/portal/conteudo/10/ProgramasReconhecidos.htm>

A análise do Quadro 2 nos permite afirmar que a Ciência da Informação no Brasil é uma área recente, ainda em estágio de formação de seus pesquisadores, já que o primeiro Doutorado específico surgiu apenas na década de 90 , mas que se fortalece na discussão de questões e no desenvolvimento do seu corpo de conhecimentos com os estudos de 
pós-graduação e a pesquisa. Pode-se perceber, também, que foi a partir de 2000 que os programas de pós-graduação no Brasil tiveram impulso.

Neste pequeno universo de onze cursos em que se constitui a pósgraduação brasileira em CI convém acrescentar algumas explicações ao quadro apresentado. Em primeiro lugar, convém destacar que o Programa do IBICT/UFF finalizou seu convênio em 2008, mas deve funcionar em conjunto até 2010 quando forem concluídas as defesas de mestrado e doutorado ainda pendentes. Em 2008 IBICT apresentou proposta e foi credenciado para associar-se novamente a UFRJ, agora com a Faculdade de Administração e Ciências Contábeis - FACC. Neste mesmo ano, a UFF (Universidade Federal Fluminense) teve seu Mestrado em Ciência da Informação credenciado.

Convém destacar, também, o da Universidade de São Paulo (USP), que de 1973 até o final de 2005 era uma área de concentração do Programa de Pós-Graduação em Comunicação, estudando objetos específicos da Informação, mas se configurando no campo da Comunicação. Só em 2006 passou a se constituir em um programa próprio em CI, credenciado para mestrado e doutorado devido à experiência anterior de seu corpo docente.

Já o Curso de Mestrado em Ciência da Informação da Universidade Federal da Paraíba (UFPB), criado em 1977, foi descredenciado pela CAPES em 2002, devido à dispersão dos temas, teorias e métodos nas dissertações de mestrado. (ARAÚJO; TENÓRIO; FARIAS, 2003). Voltou a ser reconhecido em 2007, agregando novas idéias e maior coerência.

Destaca-se também o Curso de Mestrado Profissional da Universidade de Londrina (UEL), o primeiro desta categoria na área, com uma tendência moderna de contribuir para melhorar a atuação profissional, sem descuidar dos aspectos acadêmicos.

Nesta síntese dos cursos de pós-graduação brasileiros em Ciência da Informação, cumpre lembrar o Curso de Mestrado em Ciência da Informação da PUCCAMP - Pontifícia Universidade Católica de Campinas que foi descredenciado pela CAPES na última avaliação trienal (20042006), após 30 anos de atuação, e ainda não reativado.

Merecem também menção outras formas de inserção da CI no sistema de pós-graduação, de maneira não tão específica. É o caso do Programa de Pós-Graduação em Museologia e Patrimônio promovido pela UNIRIO (Universidade Federal do Estado do Rio de Janeiro) em associação com o MAST (Museu de Astronomia e Ciências Afins), que foi credenciado e será avaliado pela CAPES pela subárea de CI.

Além disso, com a tendência moderna de agregar áreas do conhecimento, a CAPES criou uma área denominada Multidisciplinar que reúne programas não específicos de um só campo, mas que integram duas ou mais áreas do conhecimento. Assim aconteceu com quatro programas que contemplam a CI em alguns aspectos, seja na denominação, nas linhas de pesquisa ou na formação de parte de seus docentes. São eles: 

em Saúde;

FIOCRUZ (Fundação Oswaldo Cruz): Informação e Comunicação

UFSCAR (Universidade Federal de São Carlos): Ciência, Tecnologia e Sociedade;

UFPR (Universidade Federal do Paraná): Ciência, Gestão e Tecnologia da Informação;

UNIRIO (Universidade Federal do Estado do Rio de Janeiro): Memória Social.

Outro caso semelhante que apresenta alguma inserção da CI com outras áreas do conhecimento é o do PPGCOM (Programa de PósGraduação em Comunicação e Informação) da UFRGS que é credenciado e avaliado pela subárea de Comunicação, da CSA1. O PPGCOM/UFRGS que tem como área de concentração Comunicação e Informação e duas linhas de pesquisa: Comunicação, Representações e Práticas Culturais, e Informação, Tecnologias e Práticas Sociais.

Apenas para reforçar a relação da Informação com a Comunicação, especifica-se melhor o Programa da FIOCRUZ, mencionado anteriormente, que é promovido pelo Instituto de Comunicação e Informação Científica e Tecnológica em Saúde - ICICT, em níveis de mestrado e doutorado. O Programa tem como área de concentração: Configurações e Dinâmicas da Comunicação e Informação em Saúde, com duas linhas de pesquisa, a saber: Linha 1 - Informação, Comunicação e Inovação em Saúde; e Linha 2 - Informação, Comunicação e Mediações em Saúde.

\subsection{As linhas de pesquisa}

Para analisar como a CI se constitui no Brasil, através de seus programas de pós-graduação, é necessário apresentar suas linhas de pesquisa, pois é através delas que os programas indicam sua real vocação. As linhas de pesquisa aglutinam as investigações que têm afinidade entre si, e a elas se filiam os projetos de pesquisa dos docentes e, conseqüentemente, as dissertações e teses que orientam.

Neste estudo, as linhas de pesquisa dos programas caracterizam-se como unidades de análise da CI por representarem subáreas do conhecimento. Embora possuam denominações diferenciadas, as linhas de pesquisa podem apresentar enfoques semelhantes que permitem agrupá-las em categorias temáticas. Para agrupar as Linhas de Pesquisa dos PPGCI em categorias, a fim de verificar como a CI é estudada e investigada no Brasil, utilizou-se os estudos que Lena Vânia Pinheiro, pesquisadora do IBICT, vem desenvolvendo (PINHEIRO, 2005, 2006). Baseado neles, Brambilla (2007), em sua dissertação de mestrado, classificou as linhas de pesquisa dos sete programas existentes na época. As categorias adotadas, que mostram uma estrutura classificatória para a CI são: 1 Fundamentos de CI: que se compõe de temáticas estruturais; 2 Organização e Processamento da Informação: formada por temáticas instrumentais; 3 - Gestão da Informação: denominadas de temáticas gerenciais; 4 - Tecnologias da Informação: formada por temáticas 
tecnológicas; 5 - Transferência da Informação: composta por temáticas socioculturais; 6 - Aplicações da Informação: que reúne os usos da informação nas mais diversas áreas.

Com base nesta categorização e na análise de conteúdo (AC) das ementas das linhas de pesquisa dos programas, ampliou-se o estudo para os 11 programas atualmente credenciados. A seguir, apresentam-se no Quadro 3 as Categorias, as Linhas de Pesquisa dos Programas de CI e a Universidade em que são desenvolvidas. Convém ressaltar que para o enquadramento em apenas uma categoria, como preconiza a AC, ignorou-se algumas temáticas que perpassavam outras categorias, adotando-se a de maior ênfase:

\begin{tabular}{|c|c|c|}
\hline CATEGORIAS & LINHAS DE PESQUISA & PPGCI \\
\hline $\begin{array}{l}\text { Categoria } 1 \text { - Fundamentos da Ciência da } \\
\text { Informação }\end{array}$ & $\begin{array}{llllll}\text { Epistemologia } & \mathrm{e} & \text { Interdisciplinaridade } & \text { na } & \text { Ciência } & \text { da } \\
\text { Informação }\end{array}$ & IBICT/UFRJ \\
\hline \multirow{7}{*}{$\begin{array}{l}\text { Categoria } 2 \text { - Organização e Processamento } \\
\text { da Informação }\end{array}$} & Fluxos da Informação & UFSC \\
\hline & Organização da Informação & UNESP \\
\hline & Arquitetura da Informação & UNB \\
\hline & Organização e Uso da Informação & UFMG \\
\hline & Organização, Estrutura e Fluxos da Informação & IBICT/UFRJ \\
\hline & Acesso à Informação & USP \\
\hline & Memória, Organização, Acesso e Uso de Informação & UFPB \\
\hline \multirow{8}{*}{ Categoria 3 - Gestão da Informação } & Informação, Sociedade e Gestão Estratégica & IBICT/UFRJ \\
\hline & Gestão da Informação e do Conhecimento & UNB \\
\hline & Informação Gerencial e Tecnológica & UFMG \\
\hline & $\begin{array}{l}\begin{array}{l}\text { Organização e Compartilhamento da Informação e do } \\
\text { Conhecimento }\end{array} \\
\end{array}$ & UEL \\
\hline & Gestão, Mediação e Uso da Informação & UNESP \\
\hline & Produção, Circulação e Mediação da Informação & UFBA \\
\hline & Fluxos e Mediações Sócio-técnicas da Informação & UFF \\
\hline & Memória da Informação científica e tecnológica & UFPE \\
\hline Categoria 4 - Tecnologias da Informação & Informação e Tecnologia & UNESP \\
\hline \multirow[t]{7}{*}{ Categoria 5 - Transferência da Informação } & Profissionais da Informação & UFSC \\
\hline & Comunicação da Informação & UNB \\
\hline & Informação, Cultura e Sociedade & UFMG \\
\hline & Informação, Cultura e Sociedade & UFF \\
\hline & Ética, Gestão e Políticas de Informação & UFPB/JP \\
\hline & Mediação e Ação Cultural & USP \\
\hline & Políticas, Tecnologias e Usos da Informação & UFBA \\
\hline Categoria 6 - Aplicações da Informação & 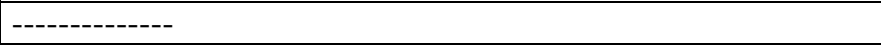 & ------- \\
\hline
\end{tabular}

Quadro 3 Categorização das Linhas de Pesquisa dos PPGCI, em 200

Fonte: dados do estudo

A análise das linhas de pesquisa mostra que a pós-graduação da área está voltada, principalmente e nessa ordem, para três vertentes temáticas: da Gestão, da Organização e da Transferência da Informação. No entanto, as Tecnologias de Informação e Comunicação, embora sejam enfocadas prioritariamente por apenas uma linha, a da UNESP (Universidade Estadual Paulista), perpassam quase todas as outras, conforme o conteúdo das ementas. Isto confirma o que Saracevic (1995) enfatiza quando diz que as tecnologias funcionam como ferramentas operacionais e técnicas da CI. 
É interessante notar, também, que apenas uma linha de pesquisa está ligada aos Fundamentos da CI. Seria importante aprofundar os estudos epistemológicos da Ciência da Informação no país, a fim de dotála de elementos constitutivos que possam estabelecer mais claramente um sistema teórico próprio e que contribua para formar sua identidade como campo científico, já que ainda se discute até mesmo seu estatuto como ciência.

Outra observação que pode ser feita em relação ao Quadro 3, é o fato de não haver uma linha de pesquisa, nos programas credenciados, para tratar especificamente das Aplicações da Informação. Pode-se amenizar a lacuna afirmando que, quase todas as pesquisas aplicadas realizadas pelos docentes e discentes dos PPGCI, são feitas em áreas especializadas. O que não existe é uma linha que trate destas aplicações de um modo concentrado e aprofundado.

Outra observação que pode ser feita em relação ao Quadro 3, é o fato de não haver uma linha de pesquisa, nos programas credenciados em CI, para tratar especificamente das Aplicações da Informação. Pode-se amenizar esta lacuna afirmando que quase todas as pesquisas aplicadas, realizadas pelos docentes e discentes dos PPGCI, são feitas em áreas específicas. O que não há é uma linha que trate destas aplicações de um modo concentrado e aprofundado. Isto possivelmente está sendo resolvido nas linhas de pesquisa do programa da FIOCRUZ que se dedica a investigar os fenômenos da Informação e da Comunicação especificamente na área da Saúde.

Um estudo paralelo sobre os vínculos institucionais dos programas de pós-graduação em CI nas Universidades brasileiras,mostra uma ligação estreita com a Biblioteconomia. Observou-se que todos os programas de pós-graduação em CI estão ligados a uma unidade universitária que oferece um curso de graduação em Biblioteconomia. Mesmo o PPGCI do IBICT, que já chegou a estar ligado à graduação e pós-graduação em Comunicação nas duas primeiras décadas de funcionamento, quando retornou a UFRJ ligou-se a uma unidade, a Faculdade de Administração e Ciências Contábeis - FACC, que abriga desde 2005 um curso de graduação em Biblioteconomia. Saracevic (1999) apontou as diferenças entre a CI e a Biblioteconomia, que o conduziram à conclusão de que são dois diferentes campos com fortes relações interdisciplinares. Pode-se acrescentar que, no Brasil, com a criação dos cursos de pós-graduação em $\mathrm{CI}$, os cursos de graduação em Biblioteconomia tiveram seus currículos e conteúdos alterados e modernizados. Mesmo aqueles cursos que não têm junto a si uma pós-graduação, mas tiveram seus docentes titulados em $\mathrm{CI}$, atualizaram suas disciplinas (matérias) e incluíram temas específicos da Ciência da Informação na formação dos bibliotecários. 


\section{Perspectivas para a representação da Ciência da Informação}

A representação da Ciência da Informação nas agências de fomento mostra um processo de institucionalização lenta, mas ao mesmo tempo evidencia o seu reconhecimento como área do conhecimento em pesquisa e na formação de recursos humanos no contexto da ciência e da tecnologia do país.

$\mathrm{Na}$ trajetória histórica, os campos da Comunicação, da Biblioteconomia, da Documentação e da Arquivologia aparecem explícitos na representação da área. A Museologia embora nunca tenha sido representada no campo da Ciência da Informação, sempre foi considerada como área afim para propósitos de financiamento de pesquisa, credenciamento e avaliação de cursos de pós-graduação. Quanto às Tecnologias da Informação a sua representação explícita na área é tímida e recente. Assim, é desejável que as comunidades científicas, tanto da CI como das áreas afins promovam discussões nos grupos de pesquisa, nos programas de ensino de graduação e pós-graduação, e nos encontros de entidades de classes sobre a CI como área do conhecimento. Esta reflexão também é importante para subsidiar uma política científica, visando o desenvolvimento harmonioso e a sedimentação da área no país.

A Ciência da Informação como área do conhecimento deve refletir o que se considera como pesquisa e ensino neste campo científico. Resta, entretanto, definir qual a forma mais adequada de se nomear essas habilidades não só no âmbito das agências de fomento, mas em outros propósitos de representação da área no universo da ciência e tecnologia do país.

Como foi mostrado, são onze, hoje, os programas específicos em CI no Brasil. No entanto, numa análise mais pormenorizada, percebe-se que a CI está inserida de alguma forma em outros programas de pósgraduação, seja na sua denominação, incluindo a palavra Informação, nas suas linhas de pesquisa, tratando de algum aspecto ou aplicação da $\mathrm{CI}$, ou na titulação de parte de seu corpo docente. Para um futuro próximo, espera-se que os programas de pós-graduação específicos em CI aumentem em número e que se distribuam melhor pelo país. De maneira especial, que seja criado um programa na Região Norte do país, onde ainda não tem nenhum curso específico na área.

Nas Universidades onde existe alguma probabilidade de criação de programas de pós-graduação em $\mathrm{CI}$, talvez devam ser oferecidos, primeiramente, cursos de especialização, como forma de inserção na pósgraduação. Entre outras estratégias que poderão contribuir para a futura criação de programas de pós-graduação pode-se citar algumas, como: titular docentes, especialmente de cursos de Biblioteconomia, em Ciência da Informação, utilizando as modalidades oferecidas pelas agências (bolsas para docentes, no país e no exterior; programas Minter de Dinter/Capes com cursos já consolidados) ou em áreas correlatas; e concursar docentes titulados em áreas com as quais a CI mantém 
interfaces, como a Informática, a Administração, e mesmo a Comunicação.

Para os cursos de pós-graduação multidisciplinares que mantém alguma interface ou relação com a CI, espera-se que, num futuro próximo, passem a focar mais a pesquisa nas temáticas próprias da área, para que venham a se desdobrar em programas específicos, aumentando numérica e qualitativamente a pós-graduação.

Em relação à pesquisa nos programas de pós-graduação em Ciência da Informação no país, a análise mostrou que as linhas de pesquisa e, conseqüentemente, os projetos de pesquisa dos docentes e as teses e dissertações deles decorrentes, têm sido organizadas em torno da Organização, Gestão e Transferência de informação. A pesquisa em CI precisa se desenvolver muito mais e em todas as temáticas. Os docentes e os profissionais já titulados precisam continuar pesquisando para termos mais certezas das nossas teorias, das nossas práticas e do papel que este campo do conhecimento tem na sociedade atual.

Pelas observações e reflexões apresentadas, a CI no Brasil pode ser caracterizada como um campo científico em construção. Para acelerar esse processo, necessita discutir com mais intensidade sua representação nas agências de fomento e no sistema nacional de pós-graduação, a fim de buscar identificar os rumos que estão sendo seguidos e propor as correções, contribuindo para que o campo se organize e se conheça melhor como área do conhecimento.

\section{Referências}

ARAÚJO, Eliany Alvarenga de; TENÓRIO, Jovana Karla Gomes; FARIAS, Simarle Nóbrega de. A Produção de Conhecimento na Ciência da Informação: analise das dissertações produzidas no curso de mestrado em Ciência da Informação - CMCI/UFPB no período de 1997/2001. In: ENCONTRO NACIONAL DE PESQUISA EM CIÊNCIA DA INFORMAÇÃO, 5, Belo Horizonte, 2003. Anais... Belo Horizonte: Escola de Ciência da Informação da UFMG, 2003. CD-Rom.

BRAMBILLA, Sonia Domingues. Interfaces da Informação: tendências temáticas da pós-graduação. Porto Alegre, 2007. 118p. (Mestrado em Comunicação e Informação) - Universidade Federal do Rio Grande do Sul - UFRGS, Porto Alegre, 2007.

CONSELHO NACIONAL DE DESENVOLVIMENTO CIENTÍFICO TECNOLÓGICO. Brasil. Classificação das áreas do conhecimento, versão 1 , 06/76. Brasília, CNPq, 1976.

CONSELHO NACIONAL DE DESENVOLVIMENTO CIENTÍFICO TECNOLÓGICO. Brasil. Classificação das áreas do conhecimento. Brasília, CNPq, 1978 , versão 2, 06/78. (Cadernos de Informação em Ciência e Tecnologia no. 1). 
CONSELHO NACIONAL DE DESENVOLVIMENTO CIENTÍFICO TECNOLÓGICO. Brasil. Classificação das áreas do conhecimento. Brasília, CNPq, 1982

CONSELHO NACIONAL DE DESENVOLVIMENTO CIENTÍFICO TECNOLÓGICO. Brasil. Classificação das áreas do conhecimento. Brasília, CNPq, $1984 . \quad$ Disponível em http://www.cnpq.br/areasconhecimento/index.htm

CONSELHO NACIONAL DE DESENVOLVIMENTO CIENTÍ́FICO TECNOLÓGICO. Brasil. Classificação das áreas do conhecimento: tabela preliminar. Brasília, CNPq, setembro de 2005. Disponível em: http://www.cnpq.br

COORDENAÇÃO DE APERFEIÇOAMENTO DE PESSOAL DE NÍVEL SUPERIOR. CAPES. Disponível em: <www.capes.gov.br>. Acesso em: 8 de junho de 2009.

FAUSTO NETO, Antônio. Condições da Pesquisa em Comunicação no Brasil. Revista Famecos, Porto Alegre, n.5, p.82-90, dez. 1996.

MEADOWS, Arthur. Jack. Tradições de pesquisa. In: A Comunicação científica. Trad. de Antonio Agenor Briquet de Lemos. Brasilia, D.F. Briquet de Lemos/Livros, 1999 p. 42.

PINHEIRO, Lena Vania Ribeiro. Ciência da Informação: desdobramentos disciplinares, interdisciplinaridade e transdisciplinaridade. 2006. Disponível em: http://www.uff.br/ppgci/editais/lenavanialeituras.pdf. Acesso em: 1 de julho de 2009.

PINHEIRO, Lena Vania Ribeiro. Processo Evolutivo e Tendências Contemporâneas da Ciência da Informação. Informação e Sociedade, João Pessoa, v. 15, n. 1, 2005.

POBLACIÓN, Dinah Apparecida de Mello Aguiar. Pesquisa e Pós-Graduação em Ciência da Informação e Biblioteconomia no Brasil: duas fases (1970/85 - 1986/92). In: ENCONTRO NACIONAL DOS CURSOS DE PÓSGRADUAÇÃO EM CIÊNCIA DA INFORMAÇÃO E BIBLIOTECONOMIA, 12., 1992, São Paulo. Anais... São Paulo: ANCIB, 1993. P. 11-23.

SARACEVIC, Tefko. Interdisciplinary Nature of Information Science. Ciência da Informação, Brasília v. 24, n. 1, p. 36-41, jan./abr. 1995.

SARACEVIC, Tefko. Information Science. JASIS; Journal of The American Society for Information Science, New York, v.50, n.12, p.1051-1063, 1999.

SOUZA, Rosali Fernandez de. Áreas do conhecimento. DataGramaZero, v.5 n.2 abril 2004. Disponível em: http://www.dgz.org.br/abr04/Art 02.htm

SOUZA, Rosali Fernandez de. A representação da Ciência da Informação como área do conhecimento no âmbito das agências de fomento. In: 
COLÓQUIO MEDIAÇÕES E USOS DE SABERES E INFORMAÇÃO: um diálogo França-Brasil. Anais ... Rio de Janeiro: Rede MUSSI, 2008. p.112-124.

STUMPF, Ida Regina Chitto. Programas de pós-graduação em Ciência da Informação no Brasil: linhas de pesquisa, avaliação e perspectivas. In: COLÓQUIO MEDIAÇÕES E USOS DE SABERES E INFORMAÇÃO: um diálogo França-Brasil. Anais ... Rio de Janeiro: Rede MUSSI, 2008. p.82-98.

ZINS, Chaim. Knowledge Map of Information Science: issues, principles, implications c.1999 Disponível em http://www.success.co.il/is/index.html 